\title{
Selective picomolar detection of mercury(II) using optical sensors $\dagger$
}

\author{
César Díez-Gil, ${ }^{a b}$ Rosario Martínez, ${ }^{c}$ Imma Ratera,${ }^{a b}$ Thomas Hirsh, ${ }^{d}$ Arturo Espinosa, ${ }^{c}$ \\ Alberto Tárraga, ${ }^{c}$ Pedro Molina, ${ }^{c}$ Otto S. Wolfbeis ${ }^{d}$ and Jaume Veciana ${ }^{* a b}$
}

Received 8th November 2010, Accepted 12th November 2010

DOI: $10.1039 / \mathbf{c 0 c c 0 4 8 6 0 g}$

The rational design of a mercury(II) ligand consisting in a 1-(4'-oxyphenyl)-4(1'-pyrenyl)-2,3-diaza-1,3-butadiene receptor unit, optimizes the sensitivity and reliability of a SPR sensor by the formation of a well packed SAM over the gold surface. SPR analysis allows detecting mercury(II) concentrations in aqueous systems in the picomolar range, meliorating on three orders of magnitude the $\boldsymbol{E} U$ mercury(II) detection limit in drinkable water.

In spite of causing serious and detrimental effects on the environment and living beings, the world's contamination with mercury has increased in the recent decades. Mercury pollution can occur as a result of a variety of natural and anthropogenic sources. ${ }^{1}$ Even though elemental and inorganic mercury species are hazardous for mammals the risk increases once these substances are introduced into the aqueous environment. There, some aquatic microorganisms are able to transform mercury(II) ions into liposoluble methylmercury, which subsequently bioaccumulates into the adipose tissue of fishes and marine mammals, ${ }^{2}$ to be later spread out into the nutritional chain. Methylmercury has a high potential neurotoxic activity and is involved in several mercury pollution-related diseases. ${ }^{3}$ In order to control the presence of such a pernicious substance and to increase our understanding on the deleterious effects of exposure to mercury, monitoring the presence of mercury(II) ions in water sources has become a priority task for governmental agencies and regulatory commissions. In addition, stringent regulations have been imposed in terms of maximum permitted limits of mercury ions in water. Thus, the European Union has dictated $1 \mathrm{ppb}$ as being a tolerable limit for mercury(II) ions in drinking water. ${ }^{1 b, c}$

Although there are several molecular mercury detectors, those based on the use of a solid substrate are limited. ${ }^{4}$ Many have shortcomings in terms of real applications, such as a lack of selectivity, complexity, water stability, or high costs. The development of an affordable, practical and reliable mercury sensor will represent a major leap for the "in situ" control of

${ }^{a}$ Departament de Nanociència Molecular i Materials Orgànics,

Institut de Ciència de Materials de Barcelona,

Consejo Superior de Investigaciones Cientificas (CSIC),

Campus U.A.B., 08193 Bellaterra, Spain.

E-mail: vecianaj@icmab.es; Fax: + 34935805729

${ }^{b}$ Networking Research Center on Bioengineering,

Biomaterials and Nanomedicine (CIBER-BBN)

Campus U.A.B., 08193 Bellaterra, Spain. Fax: + 34935805729

${ }^{c}$ Departamento de Química Orgánica, Universidad de Murcia,

Campus Espinardo, 30100 Murcia, Spain

${ }^{d}$ Institute of Analytical Chemistry, Chemo- and Biosensors,

University of Regensburg, 93040 Regensburg, Germany

$\dagger$ Electronic supplementary information (ESI) available: Experimental section and further characterization of the SAM monolayer and the SPR mercury(II) recognition process are stated here. See DOI: $10.1039 / \mathrm{c} 0 \mathrm{cc} 04860 \mathrm{~g}$

contaminated water, and will strongly reduce the fine need for the detection time. Among the available optical sensing techniques, surface plasmon resonance (SPR) is one of the most sensitive. ${ }^{5}$ Highly specific SPR sensors are usually based on the proper modification of a metal surface with a selfassembled monolayer (SAM) containing ligand molecules as recognizing elements. ${ }^{6}$ Most of the SPR-based sensors available in the market or reported in the literature are focused on the recognition and detection of large biomolecules ${ }^{7}$ and only a few have been shown to work with analytes of low molecular weight, ${ }^{8}$ let-alone those for metals or ions.

Herein we present, to the best of our knowledge, the first reusable mercury(II) SPR sensor able to perform "on flow" detection of concentrations of this highly toxic metal ion in aqueous systems in the picomolar range, meliorating on two orders of magnitude results obtained on previous optical sensors ${ }^{4 d, 8 b}$ reaching detection levels of atomic adsorption techniques without losing the receptor core intrinsic selectivity versus the most common mono, di and trivalent cations (Scheme 1).

Previous published works ${ }^{4 b, 9}$ have demonstrated that certain derivatives of 2,3-diaza-1,3-butadiene can act as sensitive and very selective molecular probes for mercury(II). Although the use of fluorescent methods has allowed us to reach mercury(II) sensitivities matching the legal concentration limit for drinkable water, ${ }^{4 b}$ the use of more sensitive techniques might permit going to even lower concentrations. Herein we present the comparison of two mercury(II) molecular receptors (1 and 2) as novel SPR sensing systems. While $\mathbf{1}$ consists only in a simple modification of the sensor core bearing a thioether group, compound 2 presents a rational design (see ESI $1 \dagger$ ) where the 1-(4'-oxyphenyl)-4(1'-pyrenyl)-2,3-diaza-1,3-butadiene receptor unit has been extensively modified with the purpose of ameliorating its self-assembling properties without modifying the sensing characteristics. In order to increase the final wettability and flexibility of the sensor a layer of hydrophilic triethyleneglycol spacer has been attached to the receptor core followed by a hydrophobic alkyl linker used as packing driving force for the assembling. A thioacetyl unit has been used to

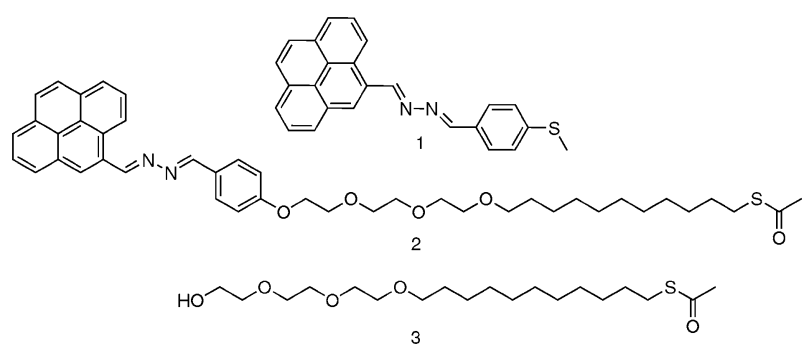

Scheme 1 SAMs building blocks for mercury(II) recognition. 
anchor the molecule to the gold surface of the sensor chip. This design can also prevent unspecific absorption, ${ }^{10}$ increase selectivity, and optimize sensitivity and reliability of the sensor by formation of a well packed SAM (Scheme 1).

Next, redox coupled assisted cyclic voltammetry (CV) studies of freshly prepared SAMs were carried out ${ }^{11}$ (see ESI $2 \dagger$ ) in order to determine the quality and packing of SAMs derived from receptors $\mathbf{1}$ and $\mathbf{2}$. Results obtained with compound $\mathbf{2}$ show a slightly higher coverage $(97.5 \%)$ if compared with the $91.5 \%$ of compound $\mathbf{1}$.

The coverage results are in agreement with those obtained for advancing and receding contact angle (CA) measurements for both monolayers (see ESI $3 \dagger$ ) which indicate high hysteresis, and therefore a worse packing and stability, for the SAM of compound 1. It is also possible to observe that static CA measurements show hydrophobic values $\left(97.6^{\circ}\right.$ and $\left.92.9^{\circ}\right)$ for the monolayers of compounds $\mathbf{1}$ and $\mathbf{2}$, respectively, in agreement with those expected for pyrene-terminated compounds. ${ }^{12}$ However, after contacting the SAMs with an aqueous solution of mercury(II) perchlorate (see ESI $3 \dagger$ ) the wettability was increased to $75.4^{\circ}$ and $71.6^{\circ}$ which is explained by the process of mercury(II) recognition.

The presence of mercury(II) ions may affect the stability of the sulfur-gold bond ${ }^{13}$ and thus, the integrity of the monolayer. This was investigated by measuring the time dependence of the $\mathrm{CV}$ curves of a mercury enriched $\left(10^{-5} \mathrm{M} \mathrm{Hg}\right.$ (II)) aqueous electrolyte solution and using SAMs of $\mathbf{1}$ and $\mathbf{2}$ on gold as working electrodes (see ESI $2 \dagger$ ). Results obtained for the two freshly prepared SAMs show desorption of compound $\mathbf{1}$ ( $22 \%$ after $10 \mathrm{~min}, 100 \%$ after $30 \mathrm{~min}$ ). Data obtained for the monolayer of the probe $\mathbf{2}$, in contrast, indicate no desorption even after $30 \mathrm{~min}$ of exposure. Thus, it is possible to establish that SAMs of compound $\mathbf{2}$ are arranged in better packing and are stable even in the presence of mercury(II) ions despite their high affinity to sulfur species.

Due to the low stability of SAMs of compound $\mathbf{1}$ in the presence of mercury ions, further experiments were carried out with SAMs of compound 2. X-Ray photoelectron spectroscopy (XPS) reveals the characteristic signals for $\mathrm{C} 1 \mathrm{~s}$ and $\mathrm{N} 1 \mathrm{~s}$ corresponding to the $\mathrm{C}$ and $\mathrm{N}$ atoms of the SAM of compound 2 (see ESI $4 \uparrow$ ). Thus, a freshly prepared SAM of compound 2 was immersed for two hours into an aqueous $10 \mu \mathrm{M}$ solution of $\mathrm{Hg}\left(\mathrm{ClO}_{4}\right)_{2}$, rinsed with MilliQ water, and dried with a stream of nitrogen. The XPS measurements showed that the peaks related to the $\mathrm{C} 1 \mathrm{~s}$ were not affected by mercury(II) ions, but that the $\mathrm{N} 1 \mathrm{~s}$ spectrum revealed a small shoulder at higher binding energies $(400.9 \mathrm{eV})$, characteristic of a $\mathrm{N}$ atom that is complexing a metal ion. ${ }^{14}$ This observation is in line with the appearance of two peaks at 100.2 and $104.4 \mathrm{eV}$ which agrees with the expected signals of a complexed mercury(II) ion (see ESI $4 \dagger$ ). ${ }^{14 b, 15}$ Therefore, one can conclude that the sensing properties of the receptor remain unchanged upon formation of the monolayer. In order to further characterize the SAMs, they were submitted to matrixassisted laser desorption/ionization time of flight (SAMDI-TOF) mass spectrometry ${ }^{16}$ before and after mercury treatment $\left.\left(10 \mu \mathrm{M} \mathrm{Hg}(\mathrm{ClO})_{4}\right)_{2}\right)$. The SAMDI-TOF mass spectrum of the mercury-free SAM of compound 2 (see ESI $5 \dagger$ ) reveals a peak at $m / z 709.28$ corresponding to the molecular peak.
Furthermore peaks are observed at $\mathrm{m} / z$ values of 492.99 , $380.01,347.90,241.96$, and 227.76 which are assigned to fragments of the attached chain of the receptor core. If compared to those obtained after mercury(II) treatment two new peaks at $m / z 478.22$ and 283.03 appear, which can be assigned to a $2: 1$ and $2: 2$ ligand:mercury(II) stoichiometry. These two stoichiometries were corroborated by DFT quantum mechanics calculations that show the existence of two energy minima corresponding to ligand-mercury ratios of $2: 1$ and $2: 2$ (see ESI $6 \dagger$ ).

Having probed the recognition properties and stability of the SAMs in the presence of mercury(II) ions, we proceed to establish the mercury recognition properties of the designed monolayer using a commercial BIOSUPLAR SPR instrument working in Kretschmann configuration equipped with a flow cell through which the control and test solutions were pumped at a constant injection flow of $100 \mu \mathrm{L}$ per minute.

Control experiments were carried out using a freshly prepared monolayer of compound $\mathbf{3}$ in order to maximize the similarity of the surfaces (see ESI $7 \dagger$ ). No signs of unspecific adsorption were observed. The same procedure was followed using a freshly prepared SAM of $\mathbf{2}$ on a gold SPR sensor chip. Upon injection of five different mercury(II) ion solutions in the concentration range from $10^{-11}$ to $10^{-7} \mathrm{M}$, in ionic strength controlled media (aqueous solution of $0.1 \mathrm{M} \mathrm{NaCl}$ ), an increase of the SPR signal was observed (Fig. 1).

Calibration of the SPR signal to refractive index units (RIU) was performed by injecting solutions of $\mathrm{NaCl}$ of different concentrations with known refractive index (Fig. 2a). Equilibrium values of the SPR signal for each concentration were used to calibrate the sensor (Fig. 2b). Sensitivity of the azine 2 based $\mathrm{Hg}^{2+}$ sensor was obtained from the slope of the calibration curve (Fig. 2b). The value obtained indicates an increase of the analytical signal of $4.58 \times 10^{-5}$ RIU per decade by increasing mercury(II) concentration. The extremely low detection limit of $2 \mathrm{ppt}$ is quite remarkable, as it reaches some atomic absorption techniques and lowers the detection limit set by the European Community by three orders of magnitude. Selectivity was tested by the injection of solutions of different
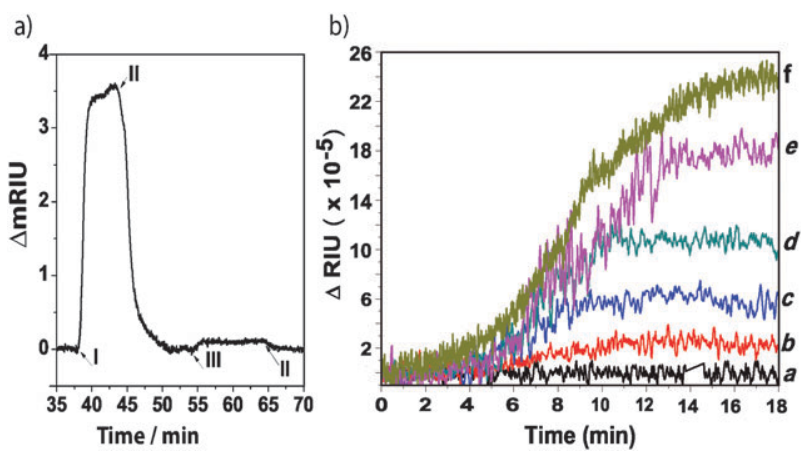

Fig. 1 (a) SPR response of a sensor chip functionalized with a SAM containing receptor 2 . Symbol I indicates the injection of $0.2 \mathrm{M} \mathrm{NaCl}$ aqueous solution as a reference solution. Symbol II (at time $42 \mathrm{~min}$ ) denotes washing with $\mathrm{NaCl}$ buffer $(0.1 \mathrm{M})$. After 54 min (denoted as III) the sensor was exposed to $0.1 \mathrm{nM} \mathrm{Hg}\left(\mathrm{ClO}_{4}\right)_{2}$ solution. (b) Time dependent SPR signal variation after the injection of all the concentrations probed (a, base line; $\mathrm{b}, 10^{-11} \mathrm{M} ; \mathrm{c}, 10^{-10} \mathrm{M} ; \mathrm{d}, 10^{-9} \mathrm{M}$; e, $\left.10^{-8} \mathrm{M} ; \mathrm{f}, 10^{-7} \mathrm{M}\right)$. 

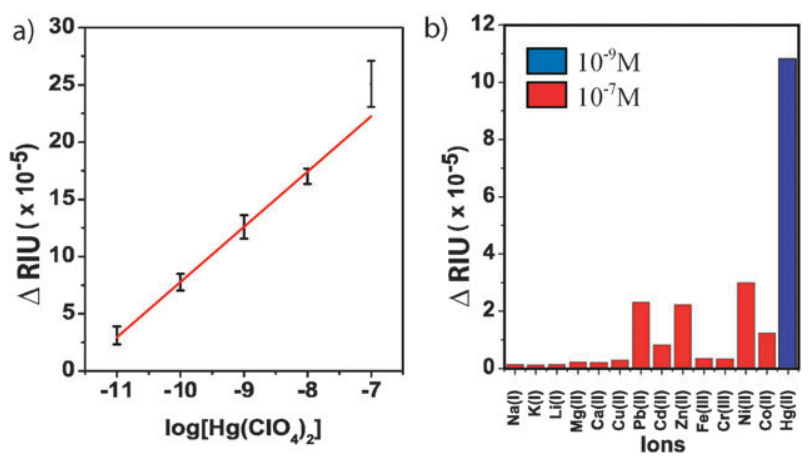

Fig. 2 (a) Calibration curve corresponding to the injection of $\mathrm{Hg}\left(\mathrm{ClO}_{4}\right)_{2}$ aqueous solutions ranging from $10^{-11} \mathrm{M}$ to $10^{-7} \mathrm{M}$; (b) selectivity tests of the sensor chip versus different solutions of cations at concentrations 100 times higher than that of mercury(II).

cations. As shown in Fig. 2a, the sensor can distinguish mercury(II) from all the other mono- and divalent cations tested, even though its concentration is 100 times lower. Interference coefficient values lower than $5.0 \times 10^{-3}$ with respect to the mercury(II) signal were found for solutions of $\mathrm{Pb}$ (II), $\mathrm{Zn}$ (II) and $\mathrm{Ni}$ (II) ions, as well as for the rest of tested ions (see Fig. 2 for concentrations used in the interference experiments). Regeneration tests of the used monolayers are also remarkable, as they indicate the possibility of reusing the same chip up to 4 times, which brings an additional value to the feasibility of the sensor chip (see ESI $8 \dagger$ ).

The ultrasensitive detection of mercury(II) by this technique is attributed to the interaction between mercury(II) ion and the well-structured SAM of compound 2. The recognition of $\mathrm{Hg}(\mathrm{II})$ ions by the receptor not only increases the mass of the chip surface, but also separates the counter ion, thus forming a charged complex, which, according to the literature ${ }^{17}$ may cause a change in the dielectric constant of the sensing layer. Previous studies on mercury(II) recognition in solution for the receptor core $^{9 a}$ showed the change of colour and the appearance of fluorescence, factors that may also influence the SPR signal.

Kinetic studies of the mercury(II) absorption by the $\mathbf{2}-\mathrm{Au}$ monolayer were performed using the linearization method ${ }^{18}$ (see ESI 9†). Results obtained depict estimated values of $0.1168 \mathrm{~s}^{-1}$ and $3.16 \times 10^{6} \mathrm{M}^{-1} \mathrm{~s}^{-1}$ for kinetic dissociation $\left(k_{\mathrm{d}}\right)$ and kinetic association $\left(k_{\mathrm{a}}\right)$ constants, respectively, in agreement with previous $k_{\mathrm{a}}$ data achieved for the mercury(II) complexation process by the receptor core in solution. ${ }^{11 a}$ Moreover, the high value obtained for the association process allows us to comprehend the extremely high sensitivity observed for the complexation process.

In summary, a new ultrasensitive and highly selective and recyclable SPR mercury(II) sensor chip, with a detection limit at the picomolar level, which is three orders of magnitude better than the allowable limit specified by the European Community for drinkable water, has been obtained by applying rational chemical design principles of metal-organic and surface chemistry. The lack of any sample pretreatment and low sample volume $(c a .1 \mathrm{ml})$ required by this method makes it suitable for in-field analysis. Furthermore, if compared with other existing techniques, the excellent analytical properties and the efficiency of our SPR sensors make it a good alternative for the developing of infield sensor for the detection of mercury(II) ions in water sources.
This work was supported by the Dirección General de Investigación (Spain) (projects CTQ2006-06333/BQU and CTQ2008-01402), the Generalitat de Catalunya (projects 2009 SGR-00516 and XERMAE), Fundación Séneca (CARM, project 04509/GERM/06), and by CIBER-BBN, ISCIII. C.D. is grateful to MEC for a predoctoral grant.

\section{Notes and references}

1 (a) Q. Wang, D. Kim, D. D. Dionysiou, G. A. Sorial and D. Timberlake, Environ. Pollut., 2004, 131, 323; (b) European Union, OJ L 330/42 5.12.98, 1998; (c) EPA (US Environmental Protection Agency) established the mercury(II) limit on 2 ppb, 2006, EPA-HQ-OPPT-2005-0013; (d) G. Qiu, X. Feng, S. Wang and L. Shang, Environ. Pollut., 2006, 142, 549.

2 (a) D. W. Boening, Chemosphere, 2000, 40, 1335; (b) H. H. Harris, I. J. Pickering and G. N. George, Science, 2003, 301, 1203; (c) A. H. Stern, R. J. M. Hudson, C. W. Shade, S. Ekino, T. Ninomiya, M. Susa, H. H. Harris, I. J. Pickering and G. N. George, Science, 2004, 303, 763.

3 (a) P. B. Tchounwou, W. K. Ayensu, N. Ninashvili and D. Sutton, Environ. Toxicol., 2003, 18, 149; (b) I. Onyido, A. R. Norris and E. Buncel, Chem. Rev., 2004, 104, 5911.

4 (a) M. K. Nazeeruddin, D. Di Censo, R. Humphry-Baker and M. Grätzel, Adv. Funct. Mater., 2006, 16, 189; (b) C. Diez-Gil, R. Martinez, I. Ratera, A. Tarraga, P. Molina and J. Veciana, J. Mater. Chem., 2008, 18, 1997; (c) J. Xie, Y. Zheng and J. Y. Ying, Chem. Commun., 2010, 46, 961; (d) J. S. Lee, M. S. Han and C. A. Mirkin, Angew. Chem., Int. Ed., 2007, 46, 4093.

5 Surface Plasmon Resonance Sensors, Springer Series on Chemical Sensors and Biosensors, ed. J. Homola, Springer Verlag, Berlin, 2006, vol. 4

6 (a) N. Kanoh, M. Kyo, K. Inamori, A. Ando, A. Asami, A. Nakao and H. Osada, Anal. Chem., 2006, 78, 2226; (b) B. T. Houseman, J. H. Huh, S. J. Kron and M. Mrksich, Nat. Biotechnol., 2002, 20, 270; (c) M. Frasconi, D. Deriu, A. D'Annibale and F. Mazzei, Nanotechnology, 2009, 20, 505501; (d) J. Wang and H. S. Zhou, Anal. Chem., 2008, 80, 7174; (e) C. A. Mandon, L. J. Blum and C. A. Marquette, ChemPhysChem, 2009, 10, 3273.

7 (a) J. Yuan, D. Deng, D. R. Lauren, M.-I. Aguilar and Y. Wu, Anal. Chim. Acta, 2009, 656, 63; (b) Y. Wang, A. Brunsen, U. Jonas, J. Dostálek and W. Knoll, Anal. Chem., 2009, 81, 9625; (c) Y. Yu, C. Feng, A.-M. Caminade, J.-P. Majoral and W. Knoll, Langmuir, 2009, 25, 13680.

8 (a) S. Wang, E. S. Forzani and N. Tao, Anal. Chem., 2007, 79, 4427; (b) S. Chah, J. Yi and R. N. Zare, Sens. Actuators, B, 2004, 99, 216

9 (a) A. Caballero, R. Martinez, V. Lloveras, I. Ratera, J. VidalGancedo, K. Wurst, A. Tarraga, P. Molina and J. Veciana, J. Am. Chem. Soc., 2005, 127, 15666; (b) C. Díez-Gil, A. Caballero, I. Ratera, A. Tárraga, P. Molina and J. Veciana, Sensors, 2007, 7, 3481.

10 (a) G. B. Sigal, C. Bamdad, A. Barberis, J. Strominger and G. M. Whitesides, Anal. Chem., 1996, 68, 490; (b) J. Lahiri, L. Isaacs, J. Tien and G. M. Whitesides, Anal. Chem., 1999, 71, 777.

11 (a) M. Geissler, J. Chen and Y. Xia, Langmuir, 2004, 20, 6993; (b) R. Brito, R. Tremont and C. R. Cabrera, J. Electroanal. Chem., 2004, 574, 15; (c) R. Brito, R. Tremont, O. Feliciano and C. R. Cabrera, J. Electroanal. Chem., 2003, 540, 53.

12 F. Lü, Y. Fang and G. J. Blanchard, Spectrochim. Acta, Part A, 2009, 74, 991.

13 M. Cohen-Atiya, A. Nelson and D. Mandler, J. Electroanal. Chem., 2006, 593, 227-240.

14 (a) M. K. Fung, S. W. Tong, S. L. Lai, S. N. Bao, C. S. Lee, W. W. Wu, M. Inbasekaran, J. J. O'Brien, S. Y. Liu and S. T. Lee, J. Appl. Phys., 2003, 94, 2686; (b) J. Wang, B. Deng, H. Chen, X. Wang and J. Zheng, Environ. Sci. Technol., 2009, 43, 5223.

15 J. F. Moulder, W. F. Stickle, P. E. Sobol and K. D. Bomben, Handbook of X-ray Photoelectron Spectroscopy, Physical Electronics, 1995.

16 (a) V. L. Marin, T. H. Bayburt, S. G. Sligar and M. Mrksich, Angew. Chem., Int. Ed., 2007, 119, 8952; (b) M. Mrksich, ACS Nano, 2008, 2, 7.

17 H. Chen, Y.-S. Gal, S.-H. Kim, H.-J. Choi, M.-C. Oh, J. Lee and K. Koh, Sens. Actuators, B, 2008, 133, 577.

18 T. A. Morton, D. G. Myszka and I. Chaiken, Anal. Biochem., 1995, 227, 176 . 